\title{
RATIONALE, REALE, APPARENS
}

Josep Montserrat Torrents

(Universitat Autònoma de Barcelona)

\section{Definiciones}

Accedo a concebir el continuo del conocimiento como susceptible de ser dividido en dos sec-

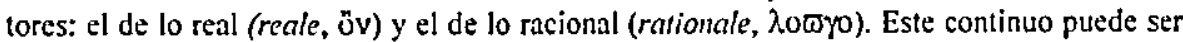
entonces aptamente designado como ontológico. Condiciono esta aceptación, sin embargo, a la posición de ambos términos como estrictamente correlativos, de tal modo que ninguno de ellos tendrá sentido sino como correlativo del otro. Tal es mi interpretación de un famoso texto de

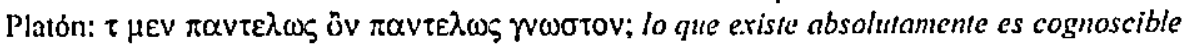
absolutamente. (Repriblica $\vee 477$ a).

El término "aparente" es asumido aqui en su acepción corriente: aquello que no es lo que

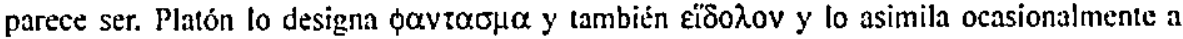

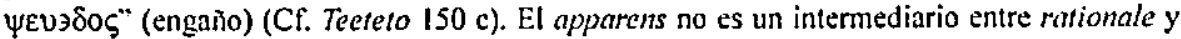
reale, sino una anomalia, o, con una metáfora no deformadora, una patología tanto de lo real como de lo racional.

Una precisa descripción de lo aparente como afección enganosa de lo real se halla en el capitulo introductorio al Comentario del Brahmasutra de Shankara donde el asentimiento a la apariencia recibe el significativo nombre de "sobreimposición" (adhyasa). Shankara distingue la sobreimposición del simple error aduciendo que aquella se produce en virtud de la apariencia.' En su grado patológico, la apariencia de lo real seria la alucinación.

Lo aparente como afección dolosa de lo racional es descrito por Platón en el Sofista, diálogo destinado a demostrar que el sofista discurre sobre apariencias y no sobre el verdadero conocimiento. ${ }^{2}$

El objeto de las presentes retlexiones en ropaje de paper es analizar la apariencia de racionalidad de un deteminado tipo de textos filosóficos. Atirmo que hay escritos filosólicos que aparentan una racionalidad que no tienen, y mostraré algunos de ellos. $A$ la apariencia de racionalidad la designaré también "apariencia de sentido". ${ }^{3}$ El término "sentido" indica aqui no sólo que una palabra o un discurso es un signo o tiene significación, sino principalmente que da lugar a interpretaciones válidas parn todos. En todo caso, el término es asumido aqui en su acepción ordinaria, expresada en frases como la siguiente: "Este signo de trálico con un cocodrilo no tiene sentido"; "El manuscrito no da sentido".

$\mathrm{Mi}$ análisis, pues, es filosófico sólo con referencia al tipo de materiales examinados. Académicamente se inscribe en los campos de la crítica literaria, de la sociología y de la psicologia.

1 The ledanta Sutra. Ilith Sumkara's Commentar?, trad. de G. Thibaud. Sacred Books of the East 34, Dover, Oxford. 1980. Véanse los primeros parralos de la Introducción de Sankiara.

2 Sofista $267 \mathrm{~d} \cdot 268 \mathrm{~d}$.

3 "En los establecimitnios de ensellanza rutinarjos y én campos tales como las litmanidades, no sólo no està claro si hay algün creciniento acumulativo, algún "progreso", sino que ni siquiera está claro cuál detxeria o podria ser el objetivo de la "investigación". Tiene que darse. sencillamente, la apariencia tanto de profindidad como de originalidad. Todo con la intención de crear la impresión de desarrollo cientifico." Ernest Gellner, l'osmodernismo, razóny religión, Paidos, Barcelona, 1994, píg. 63. 
El procedimiento es experimental, o, si se quiere, inductivo. Partiré de experiencias realizadas y de observaciones objetivables. La parquedad del trabajo de campo aducido no autorizará la propuesta de conclusiones, por lo que me limitaré a un cierto número de reflexiones.

\section{Descripción del experimento inicial}

En diciembre de 1994 participé en un simposio en Gerona que se presentaba bajo la siguiente formulación temática: "El problema de la realidad. Simulacro, frontera, intimidad." Con un mes de antelación envié a los filósofos organizadores el siguiente texto de carácter aforisticosapiencial:

\section{CONTRA EL LIMITE}

No es agradable reconocer que la infinitud desemboca en la confusión: pero también puede representar una apertura. La frontera, sin embargo. yace en mi interior, y puede pasar a ser creatividad. ¿Interior? Pues bien, interior.

Vivo mi subjetividad como: a) existencia; b) apariencia. Ahora bien, $i$ Cual es el horizonte de todo esto? El horizonte es siempre coactivo, radicalmente coactivo. Pero la libertad, ella, se halla en el interior. Por lo tanto, la frontera - aquella frontera que era el horizonte- se me conviente (se me puede convertir) en creatividad que anhela manifestarse. Dije que la subjetividad es: b) apariencia. Pues bien, las musas de hoy proclaman que el ser es presencia y que la existencia es aquello que comparece. Mis sibjlas, sin embargo, me enseñaron que la apariencia desemboca, tarde o lemprano, en la aniquilación. Y ahora, ¿qué? Da capo No es agradable....

El escrito fue recibido sin objeciones, impreso y distribuido a los participantes en el sim. posio. En su momento fue leído en sesión plenaria, recogiendo tácita aceptación. Inmediatamente después de la lectura informé a los oyentes acerca del modo de composición del texto que acababan de escuchar.

Habia extraido los veinticinco términos abstractos que aparecian en el prospecto de convo. catoria del simposio y los habia dispuesto en una lista numerada. Seguidamente habia tomado dos dados y habia aplicado un sencillo programa aleatorio que me proporcionó ocho agrupaciones de dos o tres de estos términos. Enlacé los términos dentro de cada grupo por medio de expresiones copulativas carentes de significación o de significación sumamente ambigua. Introduje inicios retóricos. Por fin, doté al conjunto de una serie de perifollos estilisticos (exclamaciones, interrogaciones, etc.). ${ }^{4}$ Es obvio que un texto obtenido por combinación alcatoria de términos no puede tener sentido, a no ser por azar. La probabilidad, para un texto de ocho agrupaciones, es remotisima. Con todo, el escrito "Contra el limite" fue recibido con toda naturalidad y no suscitó recelo alguno entre lectores y oyentes en su mayoría profesionales de la filosofia. ¿Por qué?

La respuesta a esta pregunta tiene que ser indagada en primer lugar en el ámbito de la crítica literaria, y después en el de la sociologia del conocimiento.

\section{La apariencia de sentido en el texto filosófico}

Es obvio que el escrito "Contra el limite" presentaba una apariencia de sentido, en virtud de la cual se produjo el acto anómalo del asentimiento. Debemos indagar, pues, de una manera genteral, como se produce este apparens literario.

4 Actualmente el procedimiento constituye un progmma informstico denominado "Generador de fundamentaciones, profundidades y elevaciones". introducido en lengunje Fortran en el ordenador central de la Universidad Autónoma de Barcelona (VAX VMS CCUAB l, file PARAULES). 
Todas las disciplinas del conocimiento utilizan términos abstractos, pero la filosofia es la única que se mueve casi exclusivamente entre ellos. El término abstracto puede ser claro, distinto y univoco, pero su alejamiento de la base referencial lo convierte en fácil presa de la equivocidad, de la confusión y de la anfibología. En muchas ocasiones no es el propio usuario el que realiza el acto abstractivo, sino que lo recibe ya fabricado de la tradición, proceso iniciado muchas veces en un área lingäistica ajena.

Una regla fundamental del discurso abstracto deberia ser la restricción sistemática, que excluye el uso de un tírmino abstracto fuera de su estricta genealogia lógica. La analogía y la metáfora se configuran como licencias aceptadas para obviar la sequedad de la regla, pero constituyen al mismo tiempo la fuente principal de confusión. "Nubes" llamó el comediógrafo a los pensamiertos de Sócrates. Sigámosle en la metáfora y aceptemos que de las aguas se levanten nubes y que las nubes destilen lluvia. Pero no toleraremos la navegación por el cielo nuboso, el viaje en diagonal a través de los sistemas de abstracciones. El navegante de nubes, el nefelonauta, es el tipo de intelectual que aqui estamos persiguiendo, el creador de apariencias de racionalidad y de sentido.

Si ésta es la condición del discurso filosófico, habrá que dar plena razón a Platón cuando

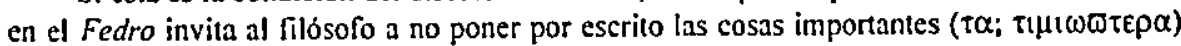
que tiene que comunicar (278 d). El discurso filosófico, debido a su intrínseca endeblez, requiere la presencia de su autor (su padre) para que responda de él, lo aclare, lo explique, lo rectilique. No hay más transmisión filosófica que la transmisión oral. El acto filosófico por antonomasia es el diálogo. ${ }^{5} \mathrm{Si}$ observamos friamente la suerte de los escritos de los filósofos no vacilaremos en acatar la sentencia platónica (transmitida, esto si, en un escrito): reinterpretación tras reinterpretación, no sabemos ya lo que pensaban Aristóteles, Plotino, Descartes o Kant. Los padres no están ya presentes para justificar a sus hijos. La escritura filosófica se disuelve en el agua regia de su propia ambición.

\section{Sociología y psicología de la comunicación filosófica}

En este apartado rellexionarí simultáneamente sobre el autor y los receptores de los textos filosóficos. Mi intento es dilucidar cuáles son las caracteristicas generales del público filosólico en virtud de las cuales se hace productor y receptor de apariencias de sentido.

La primera figura de la anomalia apariencial es el acriticismo. En ciertas circunstancias, el filósofo depone la indispensable vigilancia crítica y produce o acepta liechuras abstractas irreductibles a cualquier tipo de realidad. ${ }^{6}$

El vehículo de esta permisividad puede ser en ocasiones la autoridad, que seria la segunda figura de las patologias de lo onto-lógico.

La tercera figura podria ser la renuncia al esfuerzo por la claridad, expresada por el lema per obscuriora ad clariora, que implica una acomodación explicita al universo de la confusión.

La cuara figura es la grandilocuencia académica, muy bien denunciada por Ernest Gellner: "Los posmodemos expresan su rechazo de la disciplina oficial, su turbulencia interna profunda, mediante una prosa académica con vistas a publicar en revistas especializadas, una manera de asegurarse la promoción impresionando a los comités apropiados. Sturm und Drang und plaza de profesor numerario podría ser su lema". " La acción conjugada de estas tiguras da

5 Véase en conjunto Fedo 27.4 b - 279 a.

- Pocos pensadores tienen la sinceridad de Gadamer cuando reconoce que su problema con Dertida es que no lo entiende.

7 E. Gellner, Posmodernismo, razón y' religión, Paidos, Barcelona, 1994, pśg, 42. 
lugar a un tipo de mentalidad, activa y pasiva, proclive a la producción y a la aceptación de discursos filosóficos confusos, ambiguos, borrosos. El ingrediente de la autoridad contribuye a la consolidación de acervos de inconsistencias. Las apariencias se acumulan, se enquistan en el tejido cultural y optan al crédito magisterial. El sistema se realimenta. El nefelonauta navega impertérrito y aplaudido. Los paladares estragados ya no distinguen el agua de lluvia del agua del grifo.

Un par de ilustraciones.

PRIMERA. Un acreditado estudioso de Hegel aduce, en un libro suyo en lengua casteItana, el siguiente pasaje de la Fenomenologia del Espiritu: Este movimiento es el cielo que retorna a si. que presupone su comienzo y alcanza su final. El erudito ha of recido el texto en la traducción de Wenceslao Roces y no la ha contrastado con el original. Alıora bien, en la edjción castellana de la tradución de Roces se ha deslizado un pequeno error de imprenta: "cielo" en lugar de "ciclo" (Kreis en el texto alemán). Hegel, en efecto, habla del in sich zurückgehende Kreis. ${ }^{8}$ Pues bien, a nuestro comentarista no le arredra este cielo caido del cielo, y se despacha con el siguiente comentario: "Ahora el cielo está en la tierra porque ha retornado a si mismo. El texto debe glosarse explicando que la presuposición del término del movimiento en el origen es una presuposición en-si. Y solamente cuando el ell-si se ha desarrollado, se la convertido en para-si, es verdaderamente cielo". Y asi hasta el final de la página.

¿Cuál es el diagnóstico de este texto patológico? ¿Por qué un autor inteligente y un público avisado acogen sin pestañear la musaraina de un cielo que retorna sobre si mismo? A mi modo de ver, la responsabilidad de la anomalia se reparte equitativamente entre Hegel y su animoso comentarista. Dice Kaufinann, en su biografia de Hegel: -Por extrano que pueda sonar, (Hegel) no era incapaz de escribir con claridad, sino que llegú a parecerle que no debia ni habia de escribir del modo para el que estaba dotado". 9 De acuerdo con este curioso prin. cipio metodológico, la Fenomenologia se convirtió en un modelo ser̀ero de nefelonáutica. En este amasijo de abstracciones, un ciclo puede pasar por un ciclo sin que la suma total varie un ápice. En cuanto al comentarista hispánico, se le puede aplicar la primera de las figuras descritas anteriormente, la del acriticismo. Una actitud auténticamente filosófica, un talante crítico, hubiera plantado cara al maestro y hubiera emprendido una gestión investigadora para dilucidar los origenes de aquella frase insólita, comenzando por un indispensable recurso al texto original.

SEGUNDA. En su tesis doctoral sobre Duns Scoto, Heidegger dice que el pensamiento del franciscano hat eine gröBere und feinere Nähe (haecceitas) zum realen Leben. Cincuenta páginas más abajo hallamos la siguiente expresión: Die Form der Individualität (haecceitas). ${ }^{10}$ ¿En qué quedamos? La haecceitas es "proximidad" o es "individualidad"? Una filosofia crítica no puede aceptar sin más la sobreimposición de ambos conceptos. Todo lo más que podemos admitir es que se interseccionan, pero lo "próximo" configura un ámbito nocional distinto de lo "individual". Sin cmbargo, no he sabido hallar un sólo comentarista leideggeriano que laaya Ilamado la atención sobre esta anomalia. Por mi parte, aventuro la siguiente hipótesis: los editores de Heidegger laan confundido la haecceitas, abstracción derivada de haec, con la eccei-

8 Pag. 559 de la edición da Meiner.

9 W. Kaufmann, Hegel, Alianza Editorial, Madrid, 1972, pág. 114. Véase tambièn Nietzclue, Aurorc, 193 (citado por Kaufmann).

10 M. Heidegger, Die Kategorien- whd Bedeunngslehre des Duns Scotus (1915), en Frülı̀ Schrilten, V. K'lostermann, Frankfurt, 1978 (correspondiente al vol. 1 de la Gesamtausgald), págs. 203 y 253. Debo las citaciones a Jesủs Adrián. 
tas, término derivado de ecce. Esta ecceitas puede aptamente ser traducida por "Nähe". Los editores creyeron que el autor habia olvidado la haclue y enmendaron el texto piadosaniente. No excluyo, sin embargo, que la confusión se deba al mismo autor. La lectura nefelonáutica ha aceptado alegremente la asimilación de la proximidad a la individualidad. La etiologia del caso es la misma que la de la ilustración anterior.

\section{Sugerencias de filosofia experimental}

He aducido un experimento y un par de observaciones a guisa de soporte fáctico de un análisis puramente cualitativo. Cabe, sin embargo, una aproximación cuantitativa al fenómeno de la apariencia de sentido de los textos filosóficos. Sugiero algunas lineas de actuación.

En primer lugar, hay que actuar sobre un universo integrado exclusivamente por un público especializado. El nivel mínimo exigible sería el de estudiantes de segundo ciclo.

Un experimento sencillo es ofrecer a comentario una frase en la que se han trastocado el sujeto y el predicado (o el sintagna nominal y el sintagma verbal). Por ejemplo, mis alumnos de segundo ciclo comentaron sin arredrarse una frase de Antonio Escolotado vuelta al revés. La frase definina la metafisica como "el pensar del sentir", y la propuse como "el sentir del pensar".

E) siguiente experimento, más complejo, sería más revelador. Se proponen cuatro universos de encuesta: biólogos, economistas, comentaristas de arte y lilósofos. $A$ cada grupo se le entrega un texto compuesto aleatoriamente con términos de su respectiva especialidad y se computa el porcentaje de los que han aceptado comentarlo, independientemente del hecho de que estén o no de acuerdo con él.

Es posible incluso la autoexperimentación, seguida de autodiagnóstico. Se confeccionan un par de textos aleatorios a parir del mismo elenco de palabras. Seguidanente se procede a justificarlos y explicarlos, insistiendo en el empeno, declamando ante un interlocutor $y$ buscando citas eruditas de apoyo. Si se llega a un cierto grado de autoconvencimiento, hay que comenzar a tomar precauciones: uno está entrando por los predios de la nefelonáutica.

\section{Reflexiones de un caminante}

1. Filosofar es una aventura. Al filósofo se le obliga a discurrir por entre conceptos de la máxima abstracción, a saltar de metalenguaje en metalenguaje. El riesgo de perder la cuenta, de no acordarse del punto de salida, de no percatarse de que salió a caballo y regresa en barca, anenazan toda singladura filosófica que acepta el desafio de responder a las grandes preguntas. Huronear por el cerco del limite es una audacia; pretender traspasarlo es una temeridad; navegar por el cerco leernético es ya pura nefelonáutica. Pero abi están las preguntas.

2. La primera tarea del filósoto es explicar con toda precisión la pregunta a la cual pretende responder.

3. El lenguaje del filósoto tiene que ser básicamente el de la comunidad cula en la que se desenvuelve. Los términos técnicos y especializados deben delinirse con exactitud y no ser empleados fuera de su contexto estricto. Las metáforas deben permanecer atadas a su función analógica.

4. El filósolo debe ejercer una rigurosa autocritica de su lenguaje y del lenguaje de los demás filósofos. Una expresión tilosófica tiene que aparecer siempre lorra de toda posibilidad de mera apariencia de sentido.

5. La nebulosidad, voluntaria o involuntaria, de muchos textos filosólicos contemporáneos lia acarreado una desconfianza en el valor de la retlexión lillosótica en gentral. El públi- 
co culto no acepta discursos que intuye que pueden ser vueltos del revés como un calcetin. Si el filósofo que regresó a la caverna fue objeto de irrisión es porque decia tonterias. Hay preguntas precisas que admiten respuestas precisas, $y$ hay grandes preguntas que no tienen respuesta alguna. Nadie se reirá del filósofo que sepa discernirlas y atine a refugiarse en el silencio.

6. Solemos dar por descontado que la regresión de la enseñanza de la filosofia en los programas educativos es debida a un impulso de neobarbarie tecnológica. Es plausible pensar, sin embargo, que se trata de una malhumorada reacción frente al malbaratamiento irresponsable del tesoro de sabiduria que nos legaron los gigantes sobre cuyos hombros pretendemos mantenernos blandiendo acreditación de funcionarios del saber fílosófico.

Sean estas páginas un modesto homenaje al cientifico y filósofo que quiso poner en nuestras manos el honesto instrumento de trabajo de las ideas claras y distintas. 